\title{
On the Scientific Translation Undertaken by Gezhi Xinpao
}

\author{
Huanqi Ji, Xie Zhang \\ College of Law and Literature, Sichuan Agricultural University, Sichuan Ya'an 625014, China \\ jhq@sicau.edu.cn; zhx@sicau.edu.cn
}

Keywords: Gezhi xinpao, Science, Translation features

\begin{abstract}
Gezhi Xinpao, or Scientific Review, is a comprehensive scientific journal specialized in translating and disseminating western science and technology in late Qing dynasty (1636-1911) in China. It upholds science as an essential means to revitalize Chinese nation, and aims to publicize science through translating abundant western scientific knowledge. It is concluded that the translation work of Gezhi Xinpao is characterized by Chinese translators, domestication, rich contents, hence playing an important role in enlightening the Chinese people.
\end{abstract}

\section{Introduction}

Gezhi Xinpao is a scientific journal which was launched on March $13^{\text {th }} 1898$ in Shanghai and stopped circulation on August $8^{\text {th }}$ 1898. On it cover, it bears both English name "SCIENTFIC REVIEW" and French name "REVUE SCIENTIFIQUE". Although Gezhi Xinpao (hereinafter called Scientific Review) seemed to be short lived, it is widely acknowledged as an important scientific journal specialized in translating western science and technology. From over 20 western newspapers and journals published mainly in the United States, the United Kingdom as well as France, Scientific Review translated various contents which cover physics, chemistry, biology, medicine, astronomy, geography, military affairs, transportation, mining industry, etc, and therefore catered to the needs of different Chinese readers. The translation undertaken by Scientific Review made a great contribution to disseminating western science and technology in China and enlightening the Chinese people.

The studies of Scientific Review have been mainly conducted by Xiong Yuezhi (1994), Li Jing and Yao Yuan (2010, 2011), and Ji Huanqi (2013, 2013). However, their researches mainly focus on its disseminating knowledge of physics, chemistry, the enlightening function as well as editing features. They all seem to have ignored that Scientific Review is principally characterized by its translation of western science and technology, thus failing to present a fuller picture of such an important journal. Therefore, this paper proposes to elaborate on the translation features of Scientific Review so that a more comprehensive review of the journal can be attained.

\section{Study Background}

There was no Chinese word which is found to be quite equivalent to science in the western world before the Chinese term kexue was borrowed from Japanese. In most cases, Chinese scholars in the old time would prefer to use gezhi to describe western science. A most prominent Chinese scholar named Hu Shi (2003) pointed out in his Gezhi and Science, "When science first reached China, there was no equivalent term in Chinese. The scholars of that time translated science as gezhi." In fact, gezhi is a very important idea proposed first by Confucius in TheGreat Learning, meaning "to study the nature of things". Although this idea had been primarily used to enhance one's moral self-cultivation, it is often regarded as one of an important scientific propositions in classical Chinese epistemology. The renowned Chinese encyclopedia Ci Hai (1999) defines gezhi as "trying to study the phenomena of nature in order to acquire knowledge" or " trying to reason out the principles of nature so as to acquire knowledge". Hu Shi (2003) thus commented "Gezhi is exactly the goal of science and it is quite appropriate to have put science into Chinese as Gezhi". The Chinese name of Scientific Review - Gezhi Xinpao - actually stresses that it is journal of scientific translation. As a matte of fact, many scientific writings authored by the famous western 
missionaries like William Muirhead (1851), John Flyer (1861), W. A. P Martin (1868), Joseph Edkins (1871), Alexander Williamson (1888), etc. in the late Qing Dynasty had been entitled with gezhi as an important part of their book name.

In the first issue, Introduction to Scientific Review states clearly that "Gezhi surely should be the fundamental of governing a country”, and consequently pointed out the editing principle Scientific Review upheld. That is, it was intended to translate and disseminate western science and technology in China. Li Nanqiu (1993) made it very clearthat quite a few newspapers and journals were launched to translate and introduce much of the new scientific knowledge during the late Qing Dynasty and listed Scientific Review as one of the 38 journals and newspaper embarking on scientific translation. Fan Hongye and Wang Yangzong (1999) place Scientific Review and The Chinese Scientific Magazine in the same category, the latter of which was established by John Fryer and issued in Gezhi Workshop, the only scientific book store in Shanghai in 1885. Fan and Wang hold that "Scientific Review translates many scientific news and reports from the newspapers and journals published in France, England and America. Its contents are very rich and is quite similar to The Chinese Scientific Magazine”. As Scientific Review had set up 47 circulation sites all over China, and owned a large readership, it had consequently exerted a profound influence on the modern Chinese society. As a result, Shang Zhichong (2012) highly commends that "Scientific Review makes outstanding achievements after The Chinese Scientific Magazine in disseminating western science and technology in China.”

\section{Translation Sources of Scientific Review}

The translation sources of Scientific Review include over 22 western newspapers and journals, most of which were issued in the United States, England and France, and some of which are published in the major cities in China. Among them, 12 were written in English and 7 in French. Still other 3 were written in languages which are yet to be ascertained. It is noteworthy to mention the fact that Scientific Review translated quite a few scientific articles from the renowned North China Daily News which had been circulated in China over 100 years and had had a great influence on Chinese society. North China Daily News was first published in the name of North China Herald in Shanghai in the year of 1850. It was founded by an English businessman called Henry Shearman and was intended mainly for foreign diplomats, missionaries and merchants in China. A famous Chinese scholar of journalism named Ge Gongzhen (2011) remarked in his well-known A History of Chinese Press that "North China Daily News is a pure British newspaper, and is definitely the only mouthpiece in the East."

The contents of Scientific Review mainly consist of scientific translation from the foreign sources and account for over 70 per cent of the total. There are five major columns, ranging from Gezhi Chuguang, GezhiXinyi, NewsandReports, Editorial to QuestionsandAnswers. Gezhi Chuguang carries a series of translation from a scientific book authored by a French scientist; GezhiXinyi contains as many as 329 items, covering a very wide range of western science; QuestionsandAnswers is intended to give reply to any scientific questions from the Chinese reader. However, as such a column was hosted by a French scholar who knew little about Chinese, the contents were actually translated from a foreign source as well.

\section{Translation Features of Scientific Review}

First, all translation is independently accomplished by Chinese translators. The translators who undertook to accomplish the translation task for Scientific Review were all Chinese scholars, and served an excellent example in transforming the translation mode which had always been dominated by western missionaries. There were seven Chinese translators: Zhu Weixin, Zhang Wenbin and Zhu Fei from Jiangsu province took charge of English translation; Wang Youting, Wang Xianli, Lu Yueli and Le Zi from Zhejiang Province were responsible for French translation. All of them were carefully chosen by the founder, Zhu Zhirao, of Scientific Review, as Zhu Zhirao was a catholic proficient in both English and French. The reason why Zhu Zhirao only employed 
Chinese translators were quite carefully pondered. By the time western learning began to be spread into China toward the end of Ming Dynasty (1368-1644), there had been a popular translation mode which is usually known as "Western translation with Chinese rephrasing". That is, any western scientific material would be firstly put into Chinese by a foreigner missionary and then was polished by a Chinese. Such a collaborative translation mode was usually dominated by the foreign translator and continued even after the second Anglo-Chinese War (1856-1860). Nevertheless, as was pointed out by Ma Jianzhong (1895) in his famous Proposal of Establishing a Translation Workshop, "Foreign translators actually are far from proficient in Chinese and Chinese listeners can only guess what is told. If communication difficulties arise, Chinese listeners tend to run away with their own interpretation, thus leading to many mistakes, or even blunders.” Therefore, the elaborate choice of Chinese translators by Scientific Review can largely ensure that translation mistakes be largely eliminated in the process of communicating appropriate western learning to the Chinese readers.

Second, domestication is adopted as the primary translation strategy. Domestication is one of the most important strategies commonly used in the process of translation. As is pointed out by Friedrich Schleiermacher (1838), domestication is intended by the translator to move the author toward the reader, and leaves the reader in peace as much as possible. Lawrence Venuti (1995) formulated that domestication is "an ethnocentric reduction of the foreign text to target-language cultural values, bringing the author back home". Since China had always been regarded by the Chinese people as the center of the world since ancient time and traditional Chinese elite often thought that Chinese language and culture often occupied a quite superior position as against those outside China, this kind of self-egotism largely contributed to the fact that any western writings was supposed to be transformed in translation so that they would comply with the thousands-of-years Chinese writing norms and meantime cater to the reading taste of Chinese readers as well. The translation of Scientific Review is no exception. As all translation implies a degree of manipulation of the source language text for a certain purpose, the target language text is very likely to be brought in line with particular correctness notion. Therefore, translators of Scientific Review naturally adhered to the popular norms and endeavored to minimize the strangeness of the western scientific writings so that they could reach as many Chinese readers as possible in a popular and easy-to-understand language.

Third, the translation content is rich in various subjects. The contents of Scientific Review contain a wide range of abundant information, vivid illustrations and detailed experimental charts. The first column Gezhi Chuguang introduces a large amount of information ranging from chemistry, physics, biology, zoology, to botany and some knowledge in relation to mining industry. For ever issue, there are dozens of charts which thoroughly depicted the steps of physical and chemical experiment procedures. Elaborate pictures of a great many kinds of animals and plants are also available to the Chinese readers. The second column GezhiXinyi contains a much wider range. In the first issue, for instance, translators shared in this column as many as 25 scientific items such as coal lamp, coal consumption, paint that can change color, life-saving machine, marine cable, paper bullet, fast ship, electrical bus, new cure for cold, travel in Arctic, war affair between Germany and France, new volcano, nine long bridges, street renovation, new paper-making equipment, oil well, distance from the United States to the United Kingdom, increase of railway mileage, gold production, research on water and fire, etc. Those items extend from physics, chemistry, medicine, geography, communications, to energy and military affairs. Meanwhile, Scientific Review carries translated articles which discuss Chinese affairs like On the Future of China, Words about Weihai, On Railways in China, British Discussion on China, On the Revitalization of China, On Shanghai Market, On Eastern Affairs, Tea Trade between China and the United Kingdom, Customs of Sichuan Province. The translation of articles about Chinese affair provides a very important perspective for the Chinese readers.

\section{Significance of the Translation by Scientific Review}

The translated contents of Scientific Review closely respond to its principle of disseminating 
western science and technology in China, and are characterized by simple and straight forward diction, thus making it quite suitable for the ordinary Chinese readers who were not well-educated in the late Qing Dynasty. Such translation undertakings are commended by Xiong Yuezhi (1994) as “a model serving the general public". Much of the translated articles of Scientific Review were even copied by the important advocates of 1898 Reformation to assist their reformative campaign, commented by Fang Hanqi (1981) in his A History of Newspapers and Journal in Modern China. Great scholars like Liang Qichao and Wang Kangnian were deeply impressed simply because the translation efforts by Scientific Review made a great contribution to creating an atmosphere of learning science and enlightening the Chinese people in modern China.

\section{References}

[1] Y.Z. Xiong, Western Learning Spread to the East and the Society of Late Qing Dyansty. Shanghai People’s Press, Shanghai, 1994.

[2] J. Li, Y. Yao, GezhiXinpao and the Knowledge Dissemination of Physics and Chemistry. Journal of Northwest University, 2010, 40(4):742-746.

[3] J. Li, Y. Yao, GezhiXinpao and the Knowledge Dissemination of Geology and Astronomy. Journal of Shangluo College, 2011, 25(4):62-66.

[4] H.Q. Ji, H.Y. Gao, et al. The Editing Features of GezhiXinpao in Late Qing Dynasty. Acta Editologica, 2013, 25(1):18-20.

[5] H.Q. Ji, F. Liu, et al. The Knowledge Dissemination of Questions and Answers Column in GezhiXinpao. Chinese Journal of Scientific and Technical Periodicals, 2013, 24(5):1026-1030.

[6] Z.R. Zhu. Introduction to GezhiXinpao. Gezhi Xinpao, 1898(1):1-2.

[7] Z.G. Xia. Cihai. Shainghai: Shanghai Lexicograpy Press, 1999:3690.

[8] S. Hu. Gezhi and Science. Hu Shi. Anthology of Hushi(Vol. 8) . Hefei: Anhui Education Press, 2003:80-81.

[9] N.Q. Li. A History of Chinese Translation of Scientific Data. Hefei: Press of University of Science and Technology of China, 1993:124.

[10] H.Y. Fan, Y.Z. Wang. Western Learning Spread to the East: the Dissemination of Science in China. Changsha: Hunan Press of Science and Technology, 1999:176.

[11] Z.C. Shang. Missionaries and Western Learning Spread to the East. Taiyuan: Shanxi Education Press, 202:162.

[12] G.Z. Ge. A History of Chinese Press. Changsha: Yuelu Press,2011:73, 111.

[13] J.Z. Ma. Proposal of Establishing a Translation Workshop. Luo Xin Zhang. Anthology on Translation. Beijing: Commercial Press, 2009:192.

[14] Lawrence Venti. The Translator's Invisibility. Shanghai: Shanghai Foreign Language and Education Press, 2004:20. 